Research Article

\title{
School Children as Mini-Teachers: Exploring the impact of Child-to-Child approach in Promoting the Importance of Vitamin-A
}

\author{
Sheeba Elizabeth John Sunderraj
}

Lecturer, Sultan Qaboos University, College of Nursing, Oman.

DOI: https://doi.org/10.24321/2455.9318.202008

\section{I $\quad \mathbf{N} \quad \mathbf{F} \quad \mathbf{O}$}

E-mail Id:

sheeba.ej@squ.edu.om

Orcid Id:

https://orcid.org/0000-0002-9171-7239

How to cite this article:

Sunderraj SEJ. School Children as Mini-Teachers:

Exploring the impact of Child-to-Child approach in Promoting the Importance of Vitamin-A. Int J Nurs Midwif Res 2020; 7(1): 43-47.

Date of Submission: 2020-04-22

Date of Acceptance: 2020-06-04

\section{$\begin{array}{llllllll}\mathbf{A} & \mathbf{B} & \mathbf{S} & \mathbf{T} & \mathbf{R} & \mathbf{A} & \mathbf{C} & \mathbf{T}\end{array}$}

Background: Children are the most vulnerable part of the society who succumb to health conditions especially deficiencies of macro and micronutrients like Vitamins and Minerals. Their health is essential for an active and quality lifestyle and brings less stress on parents too. Empowering children to be masters of their own health and providing adequate knowledge regarding health aspects can promote healthy behaviors, which gradually become learned lifestyles paving way for a healthy society.

Aim: To evaluate the effect of Child-to-Child approach in teaching children about the importance of Vitamin A.

Methods: A pre experimental one group pre-test/post-test no control group design was used in this study. Using purposive sampling technique 90 children were recruited among them 18were change agents and 72 peer group.

Result: There was a significant improvement in the knowledge regarding Vitamin A and its importance to health among the children after applying the child-to-child approach. Descriptive statistics and inferential statistics like Paired ' $t$ ' test and Karl Pearson's co-efficient of correlation were used to analyse the findings. Among the pre-test and post-test scores, it was found that the knowledge level improved in their post-tests.

Conclusion: Child to child approach is a feasible method and an interesting way to get school children to learn about health. They also act responsible by being change agents.

Keywords: Vitamin-A Deficiency, Health Education, Change Agents, Child-to-Child Approach, Peer Group, School Health

\section{Introduction}

The schools have been found to be very conducive in imparting knowledge regarding health aspects. Inculcating education towards good in the young school age influence positive attitudes to health and behaviors. Health education is a mandatory component of school health programs for children. It promotes all round holistic development. Common problems of children include diseases like malnutrition, vitamin-A deficiency, anemia, worm 
infestations, dental problems, skin and other infection. ${ }^{1,2}$ In world population about more than 1.5 million are estimated to have childhood blindness. In India, $0.04 \%$ of blindness are due to vitamin-A deficiency, out of 0.7 percent of blindness of total population. ${ }^{3}$ The International declaration of rights of the child states: "The child must be given the means, requisite for the normal physical, mental, social and moral development". Young children and women of childbearing age are considered to be at greatest risk of vitamin-A deficiency. Supplementation with vitamin-A has been shown to reduce childhood mortality by 23 percent. The WHO recommends infants and children below 5 years of age with high doses of vitamin-A to improve their vitamin-A status. The provision of small doses of vitamin-A from food may be an alternative strategy for improving vitamin-A status in at risk population. ${ }^{4,5}$ Children need additional vitamin-A since they do not consume enough in their normal diet. Diets containing insufficient vitamin-A lead to decreased serum vitamin-A levels, resulting in various physiological implications. ${ }^{6}$ The home and the school are the most effective places where attempts could be made to physical, intellectual, emotional and social development in children. During the early school period from six to 14 years of age, the physiological changes are more or less at an even pace but later the problems of adolescence and puberty spurt. School health is an integral part of community health. Health knowledge and good health practices acquired by a child in the course of study in a school become a part of their way of living. The child is motivated in matters of health by another child and can influence his parents and family in the cultivation and practice of healthful habits. ${ }^{7}$

A group of health and education professionals developed the child-to-child approach for the International Year of child (1979). The Child-to-Child approach has two main goals. One is to help children gain knowledge and competence in recognizing health importance and prevention of diseases through activity-based learning that can be applied to their everyday lives. ${ }^{8}$ Second goal is developing with them the leadership quality as change agents in their own local communities. Child-to-Child approach are now used as programme across 90 different countries. These ranges from structured programs in schools to the participation of children in community health programs in urban slums. The program identifies children as "Mini- Doctors". ${ }^{9}$ It began with the gesture of an older sibling taking care and communicating with their younger ones, which later became child-to-child, child to family and children to their society in encouraging health behavioral changes. ${ }^{10,11}$

\section{Significance of the Study}

Vitamin-A deficiency is considered as a public health problem in developing countries. Vitamin-A deficiency is aggravated by lack of education, insufficient dietary intake and poor absorption leading to depleted vitamin-A stores in the body. ${ }^{12}$ School age children constitute a large number of population and are the most vulnerable to this deficiency. In order to correct this problem, school children are used as change agents. Children are found to be better change agents than the adults as they are more receptive. Children need adequate and healthy nutrition for sufficient mental development and physical growth. ${ }^{13}$ Every school syllabi has nutrition education, which forms a part always. Hence child-to-child approach is an easier and applicable method to disseminate information about health to children.

\section{Objectives of the Study}

- Identification of children as change agents for disseminating the knowledge on importance of Vitamin-A.

- Effectiveness of structured teaching program using Child-to-Child approach on dissemination of knowledge on importance of Vitamin-A.

\section{Materials and Methods}

\section{Pre-Experimental Pretest - Posttest No Control Group Design}

The research design selected for the study is pre experimental, pretest-posttest no control group design. The design is represented by $01-x-02$ where 01 is the pretest to assess the knowledge of peer group (students other than change agents) on importance of vitamin-A. $x$ is the structured teaching program to the change agents. $\mathrm{O}_{2}$ is the reassessment of the knowledge of the peer group. The knowledge of the peer group on vitamin-A is assessed before educating the change agents. The structured education is delivered to the change agents. The reassessment of the knowledge of the peer group is done to identify the information delivered by the change agents to peer group on importance of vitamin-A.

\section{Settings of the Study}

The setting of the study comprises of two schools, PSG Sarvajana Higher Secondary School, Peelamedu and PSG middle School, Vedapatti (Data collection period was 1 month). In this study, one school was selected for the pilot study (PSG Sarvajana Higher Secondary School, Peelamedu) and another school (PSG middle School, Vedapatti) was selected for the main study data collection in order to avoid data contamination.

\section{Population and Sampling}

The population initially considered from the chosen school was done by cluster sampling where the group of children were made into clusters of 10 in 15 groups having a chosen number of 150 those who met the inclusion criteria and from which some clusters were randomly selected by the 
simple random sampling method as well. Thus, the study population comprises total of 90 students (9 clusters) of VI and VII grade students. Sub clusters were also made in order to make the groups smaller and feasible for learning. Out of the total 90 students change agents selected in the ratio of 1:5. One group consists of five students, out of five, one student is a change agent and other four students were peer group. So, total number of groups were eighteen.

\section{Inclusion Criteria}

- Students of class VI \& VII

- $\quad$ For change agents-Students who can write, read and speak in both Tamil and English languages

\section{Exclusion Criteria}

For change agents- Students who cannot write, read and speak in both Tamil and English languages.

\section{Criteria for Selection of Change Agents}

Change agents were selected using a format called Identification of change agents. Identification of change agents is based on leadership qualities, communication skills, academic performance, co-curricular activities, personal activities and extra-curricular activities. The communication skills are identified through number of languages known to write, read and understand by the students. Leadership qualities of the students are assessed by the number of times the students had been a class leader, or a group leader. The first ten rank holders are selected for academic performance. The student who got first rank was given 10 marks, the subsequent rank holders are given the descending marks and the student who secured 10 'thrank got one mark. Marks are given for all these criteria's and other criteria's like co-curricular activities, extra-curricular activities which consists of participation in the competitions, prizes won in the competitions, watching television and going for additional coaching. Total marks out of all these criteria was 50 marks, those who got 37.5 (75\%) and above are selected as change agents. 24 students got 37.5 marks and above. Out of 24 students, 18 students were selected as change agents using Lottery method in the ratio 1:5. These change agents were placed as leaders in each group.

\section{Instruments and Tools of Data Collection}

The questionnaire guide consists of two sections. Demographic characteristic of students and criteria for selection of change agents. The criteria are languages known to write, read, speak, and understand and rank of the student, questions regarding class leader, hobby of the student, leader or member in various group or committees, participated in competitions and won prizes, watching television and other programmes, going for additional coaching. Child-to-Child approach questionnaire consisting of multiple choice questions to assess knowledge of the peer group on importance of vitamin-A was developed from relevant literature search and its content validity was established by sending the questionnaire to five experts in the field. Based on their review comments the modifications were made before finalizing the tool.

The questions were categorized as related to concepts of food and health, knowledge about sources of vitamin-A, signs and symptoms of vitamin - A problems related to vitamin-A deficiency, prevention of vitamin-A deficiency. The structured questionnaire consists of 16 questions of which 13 are closed ended and three are open-ended questions. Each correct answer of a question carries one mark and no negative mark for wrong answers. Open-ended question has two marks. The scores are interpreted as follows: $>75$ Percentage $=$ completely aware, 50-75 Percentage $=$ partially aware, $<50$ Percentage= unaware. After education reassessment of knowledge of peer group on importance of vitamin-A was done by using the same questionnaire. Structured teaching module on importance of vitamin-A which includes concepts of food and health, knowledge about vitamins and vitamin-A, sources of vitamin- $A$, problems related to vitamin-A deficiency, prevention of vitamin-A deficiency was developed from various literature sources and education materials. Experts in the field to ensure authenticity of the information to be delivered also reviewed this content for education. Then the content was prepared to be very simple and child friendly to understand and delivered as "Realia" by bringing the real sources of vitamin-A, making info graphics and pamphlets.

\section{Data Collection}

The main study data collection was carried out in PSG Middle School, Vedapatti. First 3 days was spent in identification of change agents. Questionnaires was distributed to the VI and VII grade students and were asked to answer it. Within 40-50 minutes, the Questionnaires were collected back. With the help of the filled formats, change agents were selected. The peer group were given pretest on importance of vitamin-A. After that, structured teaching programme on importance of vitamin-A was imparted to the change agents by the researcher. Followed by which the change agents went back to their groups and taught their peer under faculty and researcher supervision. After seven days of the teaching, posttest was conducted for two days to the peer group on importance of vitamin-A and analysis was done.

\section{Data Analysis and Interpretation}

The Data collected from the conduct of the study were tabulated, analyzed, presented in the tables and interpreted. Paired ' $t$ ' test was used to analyze the significant differences in the knowledge score of the peer group before and after child-to-child approach. 


\section{Paired ' $t$ ' test}

This test was used to find out the effectiveness of structured teaching programme on importance of vitamin-A using child-to-child approach. It was calculated by using the formula:

$$
\begin{aligned}
& \mathrm{t}=\frac{d}{S D / \sqrt{n}} \\
& \mathrm{SD}=\sqrt{\frac{\sum(d-d)^{2}}{n-1}}
\end{aligned}
$$

Here $d=$ Mean difference between pretest and post-test scores; SD = Standard deviation of the pretest and post test score; and $\sqrt{n}=$ Root of number of samples.

\section{Result and Discussion}

The demographic profile of change agents $(n=18)$ are as age between 11 to 13 years with 10 females and 8 males. The peer groups $(n=72)$ had males (30) and females (42). On concepts related to health and food among the 72 students, only three were completely aware about health and food in pretest but in posttest, it is increased to 31 .

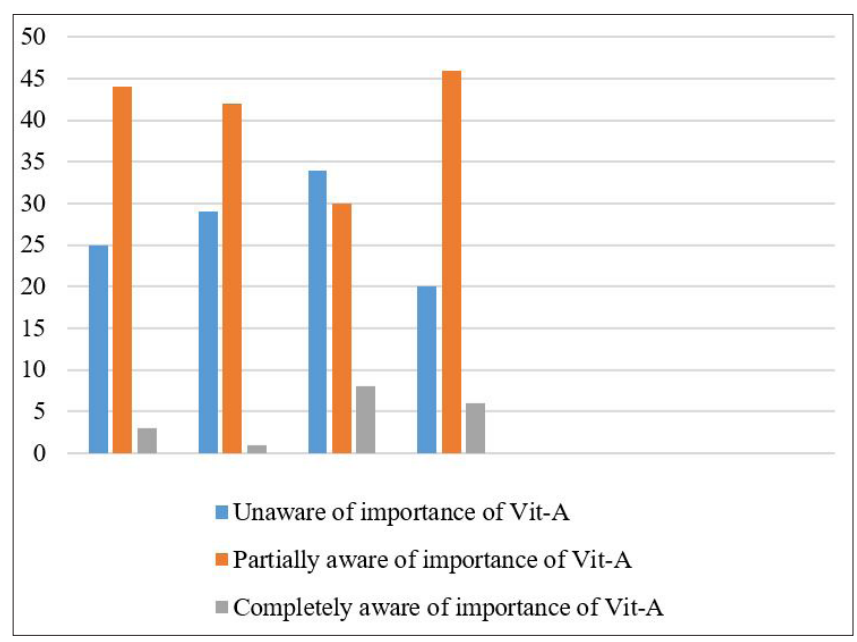

Figure I.Pretest knowledge of the peer group on importance of Vitamin-A

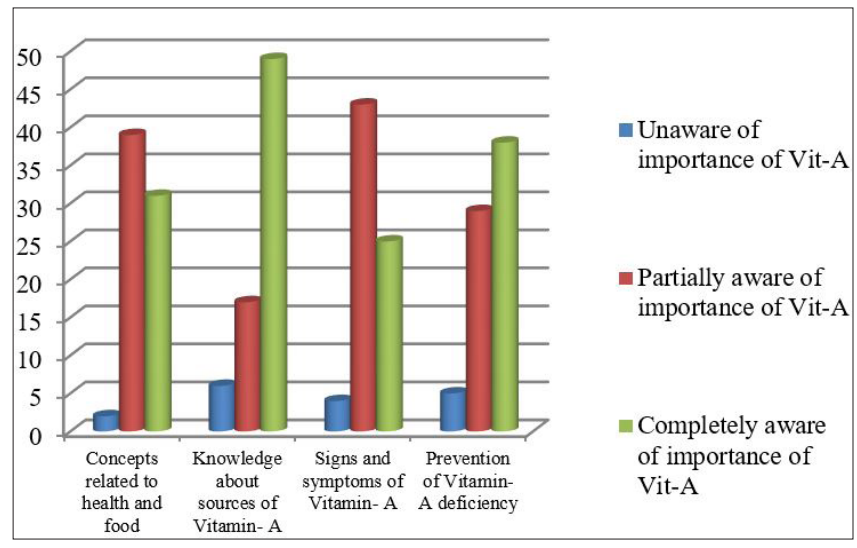

Figure 2.Posttest knowledge of the peer group after child to child approach on importance of Vitamin-A
Only one was completely aware of the knowledge about sources of vitamin-A in pretest but in posttest 49 were completely aware of the sources out of the 72. On signs and symptoms of vitamin-A deficiency only 8 were completely aware in pretest. In posttest, 25 were aware of signs of and symptoms of vitamin-A deficiency. Six were completely aware of vitamin-A deficiency in pretest. However, it is evident that 38 were completely aware of prevention aspects in post-test. The calculated mean value is 37.58 in pretest and 57.20 in posttest. The pretest standard deviation is 12.28 and the posttest standard deviation is 7.26. The paired ' $t$ ' test value is 16.09 which is greater than the table value of 3.29 at degree of freedom $(n=71)$ is significant at the level of 0.001 . This shows that there is a significant difference between the pre-test and post-test knowledge of peer group on importance of vitamin-A.

Children need education on nutrition to gain the required skills for correct selection of balanced food. A study was conducted in Iran aimed to evaluate the effect of the Child-to-Child approach based on the Theory of Planned Behavior (TPB) on the eating behaviors of elementary school students. Quasi-experimental, interventional study with pretest/posttest design was used. 173 fourth grade students were selected using multistage random cluster sampling technique. Study result showed that, child-to-child approach and TPB are effective methods in enhancement of correct eating behaviors among children. ${ }^{14}$

A similar study like the current study by Onyango-Ouma W et al. in Bondo District in Western Kenya using actionoriented participatory approach, to determine the potential of school children as health agents in a rural community. 40 school children were given health education on diarrhea, malaria and its related hygiene issues. The knowledge and practices with influence on peer groups at school and their parents at home were studied. The surveys, involved a pre-test of knowledge about diarrhea, malaria, and hygiene among participants. After the pretest surveys the peers were trained by 40 chosen school children in various groups. Posttest questionnaire was administered at 4 and 14 months. Significant improvement in knowledge was detected in all participating groups. Behavioral changes were noticed more among the children. A concrete change in the school environment and home environment was reflected as an impact of the project. The implications of the findings for health education projects and public health programmes are outlined based on the project. ${ }^{15}$ The prevalence rate of deficiency in Vitamin A is very high mainly among young children as reported in a study by Palafox NA et al. at Marshall Islands. Even 59.9\% percentage of preschoolers are affected with Vitamin A deficiency. One-third among 919 study participants' children had the co-occurrence of Vitamin A deficiency. ${ }^{16}$ 


\section{Recommendation}

Using child to adorn responsible roles for spreading health awareness will not only help in improving school health but also has its impact on the families, among peers and as the whole society. Hence, integrating the child-to-child concept into school curriculum can bring vast difference in the health promotion and prevention aspects. Further research on Child-to-Family and Child-to-Community would influence health change at the family and community level.

\section{Conclusion}

Identification of change agents in this study was done on students' leadership qualities, communication skills, academic performance, co-curricular activities, personal activities and extra-curricular activities. There was a significant improvement in the knowledge of importance of vitamin-A among VI and VII standard students after childto-child approach. The structured teaching programme using child-to-child approach was found to be effective in improving the knowledge of students, which is statistically evident. The concept of child-to-child approach promotes the understanding that children can work together with others in their communities to solve health problems. It is assumed that parents will also be willing to learn from children and include them in family health decisions.

\section{Acknowledgment}

The author preferred to acknowledge the School Secretary and the Headmaster for giving permission to conduct the study and extend thanks to the school teachers for their valuable support, guidance and the students for their active participation throughout the study.

\section{Conflicts of Interest: None}

\section{References}

1. Ananthakrishnan S, Pani SP, Nalini P. A comprehensive study of morbidity in school age children. Indian Pediatrics 2001; 38(9): 1009-1016.

2. Arlappa N, Balakrishna N, Laxmaiah A et al. Prevalence of vitamin A deficiency and its determinants among the rural pre-school children of Madhya Pradesh, India. Annals of Human Biology 2011; 38(2): 131-136.

3. Hugh H. Child-to-Child- Another path to learning, Hamburg, Unesco Institute for Education, 1988.

4. Haskell MJ, Jamil KM, Hassan F et al. Daily consumption of Indian spinach (Basellaalba) or sweet potatoes has a positive effect on total-body vitamin A stores in Bangladeshi men. The American Journal of Clinical Nutrition 2004; 80(3): 705-714.

5. Vijayaraghavan K, Radhaiah G, Prakasam BS et al. Effect of massive dose vitamin A on morbidity and mortality in Indian children. The Lancet 1990; 336(8727): 1342-5.

6. Akhtar S, Ahmed A, Randhawa MA et al. Prevalence of vitamin A deficiency in South Asia: causes, outcomes, and possible remedies. Journal of Health, Population, and Nutrition 2013; 31(4): 413.

7. Darling-Hammond L, Flook L, Cook-Harvey $C$ et al. Implications for educational practice of the science of learning and development. Applied Developmental Science 2019; 1-44.

8. Gortmaker SL, Cheung LW, Peterson KE, et al. Impact of a school-based interdisciplinary intervention on diet and physical activity among urban primary school children: eat well and keep moving. Archives of Pediatrics \& Adolescent Medicine 1999; 153(9): 975-983.

9. Mishra G. When child becomes a teacher-the child to child programme. Indian Journal of Community Medicine 2006; 31(4): 277.

10. Deepthi R, Naresh Kumar SJ, Prasanna et al. Participatory school health education on vector-borne diseases: engaging children as change agents. International Journal of Health Promotion and Education 2014; 52(2): 68-77.

11. Kolucki B, Lemish D. Communicating with children. 2011.

12. Vijayaraghavan K, Nayak MU, Bamji MS et al. Home gardening for combating vitamin A deficiency in rural India. Food and Nutrition Bulletin 1997; 18(4): 1-7.

13. Malone K. "The future lies in our hands": children as researchers and environmental change agents in designing a child-friendly neighbourhood. Local Environment 2013; 18(3): 372-395.

14. Kaveh $\mathrm{MH}, \mathrm{Nejad} \mathrm{ZK}$, Nazari $\mathrm{M}$ et al. Evaluating the effect of the child-to-child approach based on the Theory of Planned Behavior on the eating behaviors of elementary school students. Int J Med Res Health Sci. 2016; 5(5): 121-126.

15. Onyango-Ouma W, Aagaard-Hansen J, Jensen BB. The potential of schoolchildren as health change agents in rural western Kenya. Social Science \& Medicine 2005; 61(8): 1711-1722.

16. Palafox NA, Gamble MV, Dancheck B et al. Vitamin A deficiency, iron deficiency, and anemia among preschool children in the Republic of the Marshall Islands. Nutrition 2003; 19(5): 405-408. 